\title{
Evaluasi Kinerja Sistem Jaringan Drainase Panggung Lor Kota Semarang
}

\author{
Calvin Tanuwijaya ${ }^{1}$, Made Wijaya Kusuma ${ }^{2}$ \\ email: ${ }^{2}$ dan17made@gmail.com \\ Program Studi Teknik Sipil, Fakultas Teknik, Universitas Katolik Soegijapranata Semarang \\ Jalan Pawiyatan Luhur IV No.1; (024) 8441555
}

\begin{abstract}
Abstrak
Kecamatan Semarang Utara merupakan wilayah Semarang bagian utara yang terdiri dari sembilan kelurahan, salah satunya adalah kelurahan Panggung Lor. Sejak tahun 1993, banjir dan rob menjadi langganan warga kelurahan Panggung Lor, Semarang Utara. Pada tahun 2017 situasi di wilayah Panggung Lor mulai berubah. Faktor yang menyebabkan banjir di daerah Panggung Lor mulai berkurang salah satunya adalah karena bantuan stasiun pompa. Tujuan penelitian ini adalah untuk mengetahui kondisi eksisting, kapasitas saluran drainase serta menganalisis dan mengevaluasi kinerja pompa di daerah Panggung Lor. Analisa menggunakan program EPA SWMM 5.1. Pada kondisi eksisting, terdapat kerusakan pada dinding badan saluran drainase di Jalan Kuala Mas 15. Berdasarkan hasil analisis, saluran drainase yang ada di Jalan Telaga Mas Raya kelurahan Panggung Lor masih mampu menampung debit air yang mengalir sebesar $86 \%$ dengan total inflow $13,65 \mathrm{~m}^{3} / \mathrm{s}$. Pemodelan yang menggunakan periode ulang 2 dan 10 tahunan, apabila pompa aktif sesuai kondisi eksisting tidak akan menyebabkan flooding. Jika menggunakan periode ulang 25 tahunan, masih menyebabkan flooding sehingga perlu penambahan pompa dengan debit 0,7 $\mathrm{m}^{3} /$ detik di rumah pompa 3 dan 1 pompa dengan debit $1 \mathrm{~m}^{3} /$ detik di rumah pompa 4 .
\end{abstract}

Kata Kunci: Evaluasi sistem jaringan, saluran drainase, flooding, SWMM

\begin{abstract}
North Semarang Subdistrict is the northern part of Semarang which consists of nine urban village, one of it is Panggung Lor village. Since 1993, flooding and rob have been subscribed to residents of Panggung Lor village, North Semarang. In 2017 the situation in the Panggung Lor area began to change. The factors that caused flooding in the Panggung Lor area began to reduce one of them due to the help of the pumping station. The purpose of this study was to study the existing conditions, the capacity of the drainage channel, and analyze and improve the performance of the pump in the Panggung Lor area. Analysis using the EPA SWMM 5.1 program. In existing conditions, there is damage to the drainage canal wall at Jalan Kuala Mas 15. Based on the results of the analysis, the drainage channel on Telaga Mas Raya Street in the Panggung Lor sub-district can still accommodate $86 \%$ of the flowing air flow with a total flow of $13.65 \mathrm{~m}^{3} / \mathrm{sec}$. Modeling using a 2 and 10 year return period, renewing the active pump according to existing conditions will not cause flooding. If you use a 25-year return period, it still causes flooding so you need to add a pump with a discharge of $0.7 \mathrm{~m}^{3} /$ second at pump house 3 and 1 pump with a discharge of 1 $\mathrm{m}^{3} /$ second at the pump house 4 .
\end{abstract}

Keywords: Evaluation of network systems, drainage channels, flooding, SWMM 


\section{PENDAHULUAN}

\subsection{Latar Belakang}

Semarang merupakan Ibu Kota Provinsi Jawa Tengah yang mempunyai luas wilayah mencapai $373,7 \mathrm{~km}^{2}$ dan terbagi secara administratif menjadi 16 wilayah kecamatan dan 177 wilayah kelurahan. Kecamatan Semarang Utara merupakan wilayah Semarang bagian utara yang terdiri dari sembilan kelurahan, salah satunya adalah kelurahan Panggung Lor. Sejak tahun 1993, banjir dan rob menjadi langganan warga kelurahan Panggung Lor, Semarang Utara. Bahkan hingga tahun 2015, permasalahan ini masih belum dapat dipecahkan. Salah satu penyebab daerah ini masih sering terjadi banjir adalah karena daerah Semarang Utara mempunyai topografi berupa dataran rendah. Oleh sebab itu, apabila terjadi hujan maka daerah Semarang Utara sebagai hilirnya akan menerima kiriman banjir dari daerah Semarang yang lebih tinggi yang merupakan hulunya. Pada tahun 2017 situasi di wilayah Panggung Lor, Semarang Utara mulai berubah.

Warga sekitar mulai bekerja keras membersihkan drainase dan saluran. Para warga meminjam alat berat dari Dinas Pekerjaan Umum (DPU) berupa backhoe, crane dan dump truck untuk membersihkan saluran. Pemerintah Kota Semarang pun ikut memberikan bantuan dengan membuat sheet pile (dinding turap) di Kali Asin, normalisasi Banjir Kanal Barat dan membangun drainase. Faktor lain yang menyebabkan banjir di daerah Panggung Lor mulai berkurang adalah karena bantuan stasiun pompa.

\subsection{Tujuan Penelitian}

Tujuan dari penelitian ini adalah:

a. Mengetahui kondisi eksisting saluran drainase di daerah Panggung Lor, b. Mengetahui kapasitas saluran drainase terhadap banjir,

c. Menganalisis dan mengevaluasi kinerja pompa di daerah Panggung Lor.

\subsection{Manfaat Penelitian}

Adapun manfaat penelitian ini, yaitu:

a. Menambah pengetahuan terutama tentang pengaplikasian Software EPASWMM dengan sistem drainase di lapangan,

b. Mampu menerapkan ilmu yang didapatkan pada saat perkuliahan,

c. Sebagai salah satu masukan bagi pemerintah kota Semarang dalam rangka mengevaluasi kinerja pompa di daerah Panggung Lor.

\subsection{Batasan Penelitian}

Adapun batasan penelitian yang kami gunakan dalam studi penerapan ini, diantaranya:

a. Wilayah penelitian adalah Panggung Lor yang terletak di daerah Semarang Utara,

b. Sistem drainase yang diteliti adalah saluran drainase di daerah Panggung Lor Kota Semarang,

c. Penelitian ini membahas tentang menganalisis dan mengevaluasi kinerja pompa di daerah Panggung Lor Kota Semarang,

d. Analisa menggunakan program EPA SWMM 5.1.

\subsection{Lokasi Penelitian}

Ruang lingkup wilayah penelitian untuk dilakukannya analisa pemodelan dengan menggunakan EPA SWMM 5.1 adalah di daerah Panggung Lor Kota Semarang. Panggung Lor merupakan salah satu kelurahan yang terletak di Semarang bagian utara. 


\section{TINJAUAN PUSTAKA}

\subsection{Hidrograf}

Hidrograf merupakan diagram yang menggambarkan hubungan antara variasi debit dengan waktu. Hidrograf satuan adalah hidrograf limpasan langsung yang dihasilkan oleh hujan efektif yang terjadi merata di seluruh DAS dan dengan intensitas tetap selama satu satuan waktu yang ditetapkan, yang disebut hujan satuan. Sifat-sifat Hidrograf antara lain:

A. Time Lag (L)

Adalah waktu dari titik berat hujan sampai puncak hidrograf.

B. Waktu naik (rising time) tp

Adalah waktu mulai hujan sampai puncak.

C. Waktu konsentrasi tc

Adalah waktu dari akhir hujan sampai titik belok pada sisi turun.

D. Waktu turun (recession time) tr Adalah waktu dari puncak sampai akhir limpasan permukaan.

E. Waktu dasar (base time) tb

Adalah waktu dari awal sampai akhir limpasan permukaan.

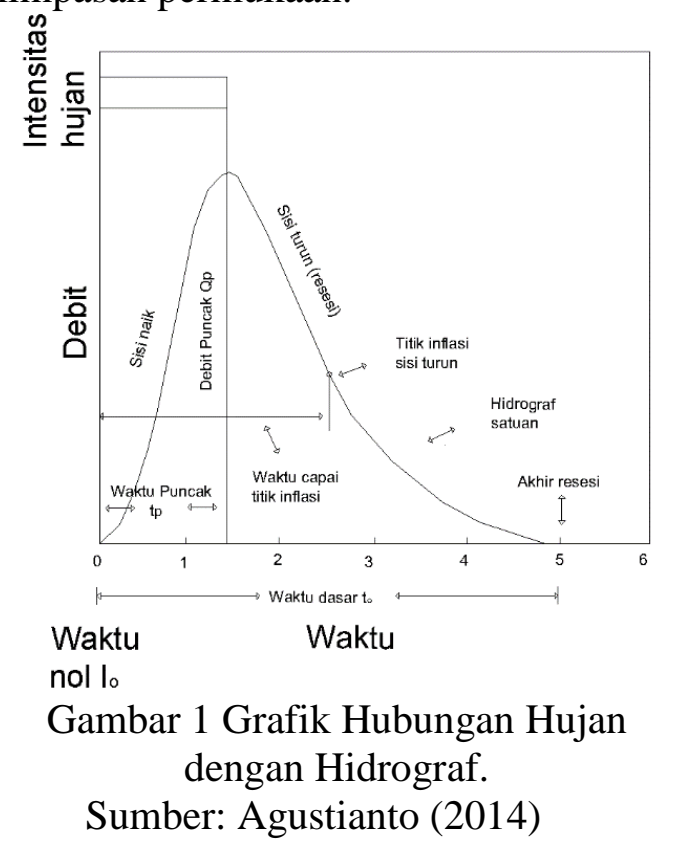

\subsection{Drainase Perkotaan}

Menurut Hasmar (2002), drainase perkotaan merupakan ilmu drainase yang mengkaji secara khusus kawasan perkotaan yang erat kaitannya dengan kondisi lingkungan fisik dan lingkungan sosial budaya yang ada di kawasan kota tersebut.

\subsubsection{Jenis-Jenis Drainase}

Jenis drainase dapat dikelompokan sebagai berikut (Hadi Hardjaja, dalam jurnal Kusumo 2009):

A. Drainase Menurut Sejarah Terbentuknya

1. Drainase Alami

Drainase yang terbentuk secara alami, tidak ada unsur campur tangan manusia serta tidak terdapat bangunan-bangunan penunjang dan gorong-gorong.

2. Drainase Buatan

Drainase yang memerlukan selokan pasangan batu, gorong-gorong, dan pipa-pipa karena dibuat dengan maksud dan tujuan tertentu.

B. Drainase Menurut Konstruksinya

1. Saluran Terbuka

Saluran yang lebih cocok untuk drainase air hujan yang terletak di daerah yang mempunyai luasan yang cukup yang tidak mengganggu lingkungan.

2. Saluran Tertutup

Saluran yang pada umumnya sering dipakai untuk aliran air kotor.

\subsubsection{Sistem Jaringan Drainase}

Menurut Allafa (2008), pada umumnya, sistem jaringan drainase dibagi menjadi 2 bagian, yaitu:

A. Sistem Drainase Mayor

Sistem drainase mayor adalah sistem saluran yang berfungsi untuk menampung dan mengalirkan air dari suatu daerah tangkapan air hujan (catchment area).

B. Sistem Drainase Mikro 
Sistem drainase mikro adalah sistem saluran dan bangunan pelengkap yang berfungsi untuk menampung dan mengalirkan air dari daerah tangkapan hujan.

\subsection{Bentuk Penampang Saluran} yaitu:

Adapun bentuk-bentuk saluran,

\section{A. Trapesium}

Bentuk saluran ini memerlukan cukup banyak ruang.

B. Persegi

Bentuk saluran ini tidak memerlukan banyak ruang.

C. Segitiga

Bentuk saluran segitiga pada umumnya diterapkan pada saluran awal yang sangat kecil.

D. Lingkaran

Saluran ini biasanya digunakan untuk gorong-gorong dimana salurannya tertanam di dalam tanah.

\subsection{Dimensi Saluran}

Perhitungan dimensi saluran didasarkan pada debit yang ditampung oleh saluran (Qs) lebih besar atau sama dengan debit rencana yang diakibatkan oleh hujan rencana $\left(\mathrm{Q}_{\mathrm{T}}\right)$. Kondisi demikian dapat dirumuskan dengan persamaan berikut:

$$
\mathrm{Qs} \geq \mathrm{Q}_{\mathrm{T}}
$$

Debit yang mampu ditampung oleh saluran (Qs) dapat diperoleh dengan rumus seperti di bawah ini:

$\mathrm{Qs}=\mathrm{A} \times \mathrm{V}$

dimana,

$\mathrm{A}=$ Luas penampang saluran $\left(\mathrm{m}^{2}\right)$

$\mathrm{V}=$ Kecepatan rata-rata aliran di dalam saluran $(\mathrm{m} / \mathrm{det})$

\footnotetext{
Kecepatan rata-rata aliran di dalam saluran dapat dihitung dengan menggunakan rumus Manning sebagai berikut:

$\mathrm{V}=\frac{1}{n} r^{2 / 3} S^{1 / 2}$

$\mathrm{r}=\frac{A}{p}$

dimana,

$\mathrm{V}$ = Kecepatan rata-rata aliran di dalam saluran (m/det)

$\mathrm{n} \quad=$ Koefisien kekasaran Manning

$\mathrm{R}=$ Jari-jari hidrolis (m)

$\mathrm{S}=$ Kemiringan dasar saluran

A $=$ Luas penampang saluran $\left(\mathrm{m}^{2}\right)$

$\mathrm{P}=$ Keliling basah saluran $(\mathrm{m})$

\subsection{Analisis Hidrologi}

Analisis hidrologi secara umum merupakan satu bagian analisis awal di dalam perancangan gorong-gorong, bendung, bangunan pelimpah, tanggul penahan banjir. Beberapa hal yang perlu ditinjau adalah:

A. Analisis Frekuensi Curah Hujan

Berikut empat jenis distribusi frekuensi yang paling banyak digunakan di dalam bidang hidrologi:

a. Distribusi Normal

Menurut metode distribusi normal, perhitungan curah hujan rencana mempunyai persamaan sebagai berikut:

$\mathrm{X}_{\mathrm{T}}=\mathrm{X}+\mathrm{K}_{\mathrm{T}} \times \mathrm{S}$

Keterangan:

$\mathrm{X}_{\mathrm{T}}=$ curah hujan rencana dengan periode ulang $\mathrm{T}$ tahun $(\mathrm{mm})$

$\mathrm{X}=$ rata - rata curah hujan harian maksimum (mm)

$\mathrm{S}=$ standar deviasi

$\mathrm{K}_{\mathrm{T}}=$ nilai faktor frekuensi dengan periode ulang $\mathrm{T}$ tahun

b. Distribusi Log Normal

Perhitungan curah hujan rencana untuk distribusi Log Normal menggunakan persamaan sebagai berikut:

$\mathrm{X}_{\mathrm{T}}=\overline{\mathrm{X}}+\mathrm{K}_{\mathrm{T}} \times \mathrm{S}$

Keterangan:

$\mathrm{X}_{\mathrm{T}}=$ curah hujan rencana dengan periode ulang $\mathrm{T}$ tahun (mm) 


$$
\begin{aligned}
& \overline{\mathrm{X}}=\text { rata-rata curah hujan harian } \\
& \text { maksimum }(\mathrm{mm}) \\
& \mathrm{S}=\text { standar deviasi } \\
& \mathrm{K}_{\mathrm{T}}=\text { nilai faktor frekuensi dengan } \\
& \text { periode ulang } \mathrm{T} \text { tahun }
\end{aligned}
$$

c. Distribusi Gumbel

Analisis frekuensi untuk curah hujan rancangan dengan metode Gumbel, yaitu:

$X_{T}=X+S \times K_{T}$

Keterangan:

$X_{T}=$ curah hujan rencna dengan periode ulang $\mathrm{T}$ tahun $(\mathrm{mm})$

$X=$ rata - rata curah hujan maksimum (mm)

$K_{T}=$ nilai faktor frekuensi dengan periode ulang $\mathrm{T}$ tahun

dimana nilai faktor frekuensi $\left(K_{T}\right)$ diperoleh dari persamaan sebagai berikut:

$K_{T}=\frac{Y_{T}-Y_{n}}{S_{n}}$

Keterangan:

$Y_{T} \quad=$ reduced variate

$Y_{n} \quad=$ reduced mean

$S_{n} \quad=$ reduced standard deviation

\section{d. Distribusi Log Pearson III}

Distribusi ini sering digunakan di dalam analisis hidrologi, terutama di dalam analisis data maksimum (banjir) dan minimum (debit minimum) dengan nilai ekstrim.

Setelah menentukan distribusi yang digunakan proses selanjutkan uji kecocokan distribusi yang digunakan apakah memenuhi syarat atau tidak. Pengujian dilakukan dengan 2 cara:

1. Uji Chi Kuadrat

Uji kecocokan Chi Kuadrat dilakukan dengan rumus:

$\chi^{2}=\sum \frac{(E f-O f)^{2}}{E f}$

Keterengan:

$\chi^{2}=$ harga chi kuadrat
$E f=$ jumlah nilai teoritis tiap sub kelompok

of $=$ jumlah nilai pengamatan tiap sub kelompok

2. Uji Smirnov Kolmogorov

Uji Smirnov Kolmogorov disebut juga uji non parametik karena pengujian tidak menggunakan fungsi distribusi tertentu.

B. Analisa Intensitas Curah Hujan Intensitas hujan dapat dihitung dengan rumus Mononobe:

$I=\frac{R 24}{24}\left(\frac{24}{t}\right)^{2 / 3}$

dimana,

$\mathrm{I}=$ Intensitas hujan $(\mathrm{mm} / \mathrm{jam})$

$\mathrm{t}=$ Lamanya hujan (jam)

$\mathrm{R}_{24}=$ Curah hujan maksimum harian (mm)

\subsection{Rumah Pompa}

Menurut Lutfiyah (2010) stasiun rumah pompa merupakan tempat yang digunakan oleh pompa air untuk memindahkan atau menaikkan debit air serta mengatur besarnya air yang dapat dikeluarkan oleh pompa tersebut.

\subsection{EPA-SWMM}

Storm Water Management Model (SWMM) adalah model simulasi hujan aliran yang digunakan untuk simulasi kuantitas maupun kualitas limpasan permukaan dari daerah perkotaan.

\section{METODE PENELITIAN}

\subsection{Konsep Pikir}

Metode penelitian ini menggunakan metode studi kasus dan pemodelan. Konsep pikir penelitian ini dimulai dengan melakukan pengamatan di lapangan. Setelah itu, dilakukan pengumpulan data dilanjutkan dengan melakukan pengolahan data dan analisis data. Konsep pikir di atas akan diperjelas sebagai berikut: 
1. Identifikasi jaringan drainase (termasuk stasiun pompa).

2. Mengukur dimensi saluran drainase.

3. Melihat peta Topografi untuk menentukan batas subcatchment.

4. Memilih data curah hujan harian maksimum.

5. Memilih jenis distribusi frekuensi.

6. Melakukan uji Chi Kuadrat dan Uji Smirnov Kolmogorov.

7. Menghitung distribusi hujan jamjam an sebagai input time series.

8. Melakukan menggunakan EPA SWMM.

9. Pemodelan dilakukan sesuai dengan kondisi eksisting dan pengoptimalan pompa.

\section{ANALISA DAN PEMBAHASAN 4.1 Kondisi Eksisting Saluran Drainase Panggung Lor}

Luas wilayah kelurahan panggung lor adalah $\pm 123,47$ ha dan terdiri dari 124 RT dan 14 RW dengan jumlah penduduk sebanyak 14.113 jiwa.

Adapun batas wilayah kelurahan

Panggung Lor secara administratif adalah sebagai berikut:

1. Sebelah Utara

2. Sebelah Timur : Laut Jawa Kuningan

3. Sebelah Selatan : Kelurahan Panggung Kidul

4. Sebelah Barat : Sungai Banjir Kanal Barat

Pada saat ini, masih terdapat beberapa saluran di kelurahan Panggung Lor yang fungsinya kurang optimal. Beberapa faktornya adalah dinding badan saluran drainase yang sudah rusak (di Jalan Kuala Mas 15).

\subsection{Analisa Hujan Rencana}

\subsubsection{Data Hujan}

Data yang digunakan adalah data curah hujan harian maksimum. Stasiun hujan yang digunakan hanya 1 yaitu Stasiun Hujan Maritim Semarang dengan panjang periode data dari tahun 2004-2014 (11 tahun).

\subsubsection{Pemilihan Jenis Distribusi Frekuensi}

Berdasarkan data curah hujan maksimum selama periode 2004-2014, dapat dihitung nilai curah hujan rencana dengan menggunakan empat jenis distribusi. Berdasarkan hasil perhitungan dan uji kecocokan yang dilakukan, yang memenuhi persyaratan adalah jenis distribusi Log-Pearson III.

\subsubsection{Perhitungan Intensitas Curah Hujan Rencana}

Perhitungan intensitas curah hujan menggunakan metode Mononobe dengan menggunakan rumus sebagai berikut:

$I=\frac{R_{24}}{24} \times\left(\frac{24}{t}\right)^{2 / 3}$

Keterangan:

I = Intensitas Curah Hujan ( $\mathrm{mm} / \mathrm{jam})$

$R_{24}=$ Curah Hujan Maksimum dalam 24 jam (mm)

$t$ = Lamanya curah hujan (jam)

4.3 Pemodelan

Pada pemodelan akan dilakukan dua simulasi, yaitu simulasi sesuai dengan kondisi eksisting dan simulasi dengan mengoptimalkan kinerja pompa yang ada.

\subsubsection{Simulasi 1 (Sesuai kondisi eksisting)}

Pemodelan dilakukan sesuai dengan kondisi eksisting dimana rumah pompa yang bekerja terletak di 7 titik lokasi. Sistem jaringan drainase dimodelkan menggunakan software EPA SWMM, dan komponen yang diperlukan yaitu: 
Daerah tangkap hujan dengan sistem drainase yang langsung mengalir ke muara.

Tabel 1 Nilai Parameter Subcatchment Panggung Lor

\begin{tabular}{|c|c|c|c|c|c|}
\hline $\begin{array}{c}\text { Na } \\
\text { ma }\end{array}$ & $\begin{array}{c}\text { Lua } \\
\text { S } \\
(\mathbf{H a})\end{array}$ & $\begin{array}{c}\text { \% } \\
\text { Slo } \\
\text { pe }\end{array}$ & $\begin{array}{c}\text { \% } \\
\text { Imper } \\
\text {-vious }\end{array}$ & $\begin{array}{c}\mathbf{N}- \\
\text { Imper } \\
\text {-vious }\end{array}$ & $\begin{array}{c}\boldsymbol{N}- \\
\text { Per- } \\
\text { vious }\end{array}$ \\
\hline S7 & $\begin{array}{c}10,6 \\
0,1\end{array}$ & $\begin{array}{c}0,1 \\
5\end{array}$ & 85 & 0,011 & 0,13 \\
\hline S9 & 8,34 & $\begin{array}{c}0,1 \\
5\end{array}$ & 80 & 0,011 & 0,13 \\
\hline S22 & 7,64 & $\begin{array}{c}0,2 \\
2\end{array}$ & 75 & 0,011 & 0,13 \\
\hline
\end{tabular}

\section{Junction}

Titik sistem drainase dimana dua atau lebih saluran (conduit) bergabung.

Tabel 2 Nilai Parameter Junction

Panggung Lor

\begin{tabular}{|c|c|c|c|}
\hline Node & $\begin{array}{c}\text { Invert } \\
\text { El. } \\
(\mathbf{m})\end{array}$ & $\begin{array}{c}\text { Max. } \\
\text { Depth } \\
(\mathbf{m})\end{array}$ & $\begin{array}{c}\text { Initial } \\
\text { depth } \\
(\mathbf{m})\end{array}$ \\
\hline $\mathrm{J} 1$ & 3,05 & 1,70 & 0,20 \\
\hline $\mathrm{J} 2$ & 2,75 & 1,70 & 0,20 \\
\hline
\end{tabular}

\section{Conduit}

Saluran yang mengalirkan air limpasan serta menjadi penghubung antar junction.

Tabel 3 Nilai Parameter Conduit

Panggung Lor

\begin{tabular}{|c|c|c|c|c|c|c|}
\hline $\begin{array}{l}\text { Da } \\
\text { ta }\end{array}$ & $\begin{array}{c}\text { Inl } \\
\text { et } \\
\text { No } \\
\text { de }\end{array}$ & $\begin{array}{c}\text { Out } \\
\text { let } \\
\text { No } \\
\text { de }\end{array}$ & $\begin{array}{c}M a \\
x . \\
D e \\
p t h \\
(\mathrm{~m})\end{array}$ & $\begin{array}{c}\text { Bott } \\
\text { om } \\
\text { Wid } \\
\text { th } \\
\text { (m) }\end{array}$ & $\begin{array}{l}\text { Len } \\
\text { gth } \\
\text { (m) }\end{array}$ & $\begin{array}{l}\text { Roug } \\
\text { hness }\end{array}$ \\
\hline $\begin{array}{c}\mathrm{C} 2 \\
0\end{array}$ & $\begin{array}{c}\mathrm{J} 2 \\
3\end{array}$ & $\mathrm{~J} 22$ & $\begin{array}{c}1,0 \\
0\end{array}$ & 1,30 & $\begin{array}{c}51,1 \\
9\end{array}$ & 0,013 \\
\hline $\begin{array}{c}\mathrm{C} 2 \\
1\end{array}$ & $\begin{array}{c}\mathrm{J} 2 \\
2\end{array}$ & J21 & $\begin{array}{c}1,2 \\
0\end{array}$ & 2,60 & $\begin{array}{c}153 \\
94\end{array}$ & 0,013 \\
\hline $\begin{array}{c}\mathrm{C} 2 \\
3\end{array}$ & $\begin{array}{c}\mathrm{J} 1 \\
4\end{array}$ & J5 & $\begin{array}{c}1,2 \\
0\end{array}$ & 2,60 & $\begin{array}{c}320 \\
15\end{array}$ & 0,013 \\
\hline $\begin{array}{c}C 5 \\
6\end{array}$ & J5 & J44 & $\begin{array}{c}1,2 \\
0\end{array}$ & 2,60 & $\begin{array}{c}267 \\
28\end{array}$ & 0,013 \\
\hline
\end{tabular}

\section{Pump}

Pompa adalah penghubung yang digunakan untuk mengangkat air ke ketinggian yang lebih tinggi.

Tabel 4 Nilai Parameter Pump

Panggung Lor

\begin{tabular}{|c|c|c|c|}
\hline $\begin{array}{c}\text { Rumah } \\
\text { Pompa }\end{array}$ & $\begin{array}{c}\text { Initial } \\
\text { on/off } \\
\text { status }\end{array}$ & $\begin{array}{c}\text { Startup } \\
\text { depths } \\
\text { (m) }\end{array}$ & $\begin{array}{c}\text { Shutoff } \\
\text { depths } \\
\text { (m) }\end{array}$ \\
\hline 1 & Off & 0,75 & 0,25 \\
\hline 2 & Off & 0,40 & 0,15 \\
\hline 3 & Off & 0,75 & 0,25 \\
\hline 4 & Off & 0,75 & 0,25 \\
\hline 5 & Off & 0,75 & 0,25 \\
\hline 6 & Off & 0,75 & 0,25 \\
\hline 7 & Off & 0,75 & 0,25 \\
\hline 8 & Off & - & - \\
\hline 9 & Off & - & - \\
\hline
\end{tabular}

\section{Outfall}

Titik paling akhir dari sistem drainase.

Komponen lain yang digunakan yaitu rain gage yang berguna untuk memberi hujan rencana kepada model jaringan drainase yang telah dibuat. Data yang dipakai untuk rain gage yaitu 161,877 mm.

Pemodelan jaringan drainase diperlihatkan pada Gambar 2.

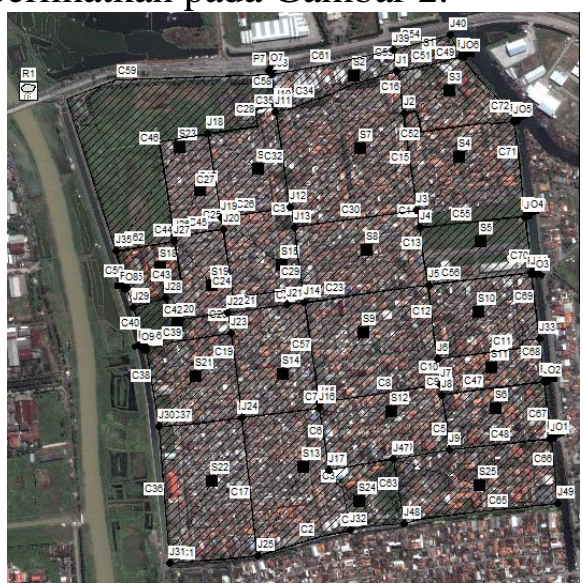

Gambar 2 Pemodelan Jaringan

Drainase. 
Simulasi selanjutnya dilakukan untuk melihat respon aliran air.

1. Pada simulasi dengan menggunakan periode ulang 2 tahunan menghasilkan nilai continuity error surface runoff adalah $-0,20 \%$ dan nilai continuity error flow routing adalah $0,00 \%$.

Selanjutnya, elevasi air tertinggi dari Junction 29 sampai Outfall 3 (saluran di Jalan Telaga Mas Raya) terjadi pada pukul 02:00. Gambar 3 memperlihatkan elevasi air tertinggi dari Junction 29 sampai Outfall 3.

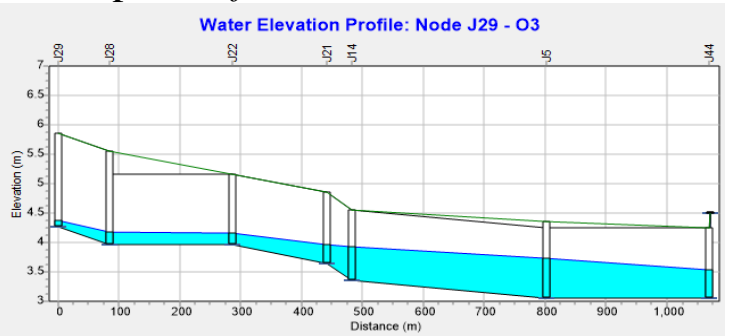

Gambar 3 Elevasi Air Tertinggi dari Junction 29 sampai Outfall 3 Periode Ulang 2 Tahunan.

2. Pada simulasi dengan menggunakan periode ulang 10 tahunan menghasilkan nilai continuity error surface runoff adalah $-0,21 \%$ dan nilai continuity error flow routing adalah $0,00 \%$.

Selanjutnya, elevasi air tertinggi dari Junction 29 sampai Outfall 3 terjadi pada pukul 02:00. Gambar 4 memperlihatkan elevasi air tertinggi dari Junction 29 sampai Outfall 3.

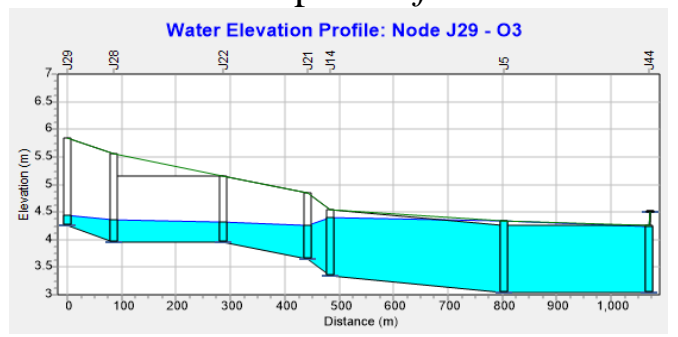

Gambar 4 Elevasi Air Tertinggi dari Junction 29 sampai Outfall 3 Periode Ulang 10 Tahunan.
3. Pada simulasi dengan menggunakan periode ulang 25 tahunan menghasilkan nilai continuity error surface runoff adalah $-0,21 \%$ dan nilai continuity error flow routing adalah $-0,04 \%$.

Selanjutnya, elevasi air tertinggi dari Junction 29 sampai Outfall 3 terjadi pada pukul 02:00. Gambar 5 memperlihatkan elevasi air tertinggi dari Junction 29 sampai Outfall 3.

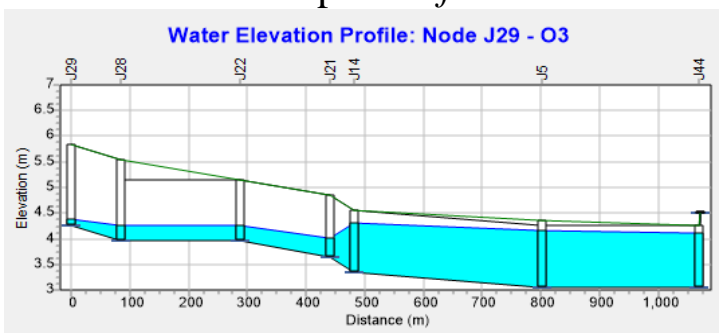

Gambar 5 Elevasi Air Tertinggi dari Junction 29 sampai Outfall 3 Periode Ulang 25 Tahunan.

\subsubsection{Simulasi 2 (Pengoptimalan pompa)}

Pada simulasi 2, pemodelan dilakukan dengan mengoptimalkan kinerja pompa yang ada di Panggung Lor Semarang.

A. Berdasarkan simulasi dengan periode ulang 2 tahunan, didapat hasil apabila menonaktifkan pompa di rumah pompa 1, 2 dan 3 tidak akan menyebabkan flooding.

B. Berdasarkan simulasi dengan periode ulang 10 tahunan, didapat hasil apabila menonaktifkan pompa di rumah pompa 1 tidak akan menyebabkan flooding.

C. Berdasarkan simulasi dengan periode ulang 25 tahunan, didapat hasil apabila menambahkan 2 pompa dengan debit $0,7 \mathrm{~m}^{3} /$ detik di rumah pompa 3 dan 1 pompa dengan debit $1 \mathrm{~m}^{3} /$ detik di rumah pompa 4 tidak menyebabkan flooding. 


\section{Kesimpulan dan Saran}

\subsection{Kesimpulan}

Berdasarkan dari hasil analisis dan pembahasan yang sudah dilakukan, maka kesimpulan yang didapatkan sebagai berikut ini:

1. Berdasarkan kondisi eksisting, terdapat kerusakan pada dinding badan saluran drainase di Jalan Kuala Mas 15.

2. Saluran drainase yang ada di kelurahan Panggung Lor masih mampu menampung debit air yang mengalir sebesar 86\% dengan total inflow 13,65 $\mathrm{m}^{3} / \mathrm{s}$ (saluran di Jalan Telaga Mas Raya).

3. Pemodelan dilakukan dengan menggunakan periode ulang 2 tahunan, 10 tahunan dan 25 tahunan.

A.Pemodelan yang menggunakan periode ulang 2 tahunan didapat hasil apabila menonaktifkan pompa di rumah pompa 1,2 dan 3 tidak akan menyebabkan flooding.

B. Pemodelan yang menggunakan periode ulang 10 tahunan didapat hasil apabila menonaktifkan pompa di rumah pompa 1 tidak akan menyebabkan flooding.

C. Pemodelan yang menggunakan periode ulang 25 tahunan didapat hasil apabila menambahkan 2 pompa dengan debit $0,7 \mathrm{~m}^{3} /$ detik di rumah pompa 3 dan 1 pompa dengan debit $1 \mathrm{~m}^{3} /$ detik di rumah pompa 4 tidak menyebabkan flooding.

\subsection{Saran}

Berdasarkan dari hasil analisis dan pembahasan yang sudah dilakukan, maka saran yang dapat disampaikan sebagai berikut ini:

1. Disarankan untuk periode ulang 25 tahunan, menambah 2 pompa dengan debit $0,7 \mathrm{~m}^{3} /$ detik di rumah pompa 3 dan 1 pompa dengan debit $1 \mathrm{~m}^{3} /$ detik di rumah pompa 4 agar tidak terjadi flooding, karena daerah yang dilayani oleh rumah pompa 3 dan 4 paling luas.

2. Pemerintah yang diwakilkan oleh kelurahan mewajibkan warga di daerah Panggung Lor untuk membayar iuran perbulan guna membiayai petugas yang akan rutin membersihkan saluran di daerah Panggung Lor.

3. Diperlukan sosialisasi kepada warga Panggung Lor untuk tidak membuang sampah sembarangan terutama di saluran yang ada karena dapat menyebabkan banjir.

\section{DAFTAR PUSTAKA}

Agustianto, D.A. (2014): Model Hubungan Hujan dan Runoff (Studi Lapangan). Skripsi. Universitas Sriwijaya.

Hasmar, H. (2002): Drainase Perkotaan. Jakarta: Universitas Islam Indonesia.

Lutfiyah, R., Arna, F., dan Ira, P. (2010): Penentuan Lokasi Rumah Pompa Kota Surabaya Menggunakan Metode Analytical Hierarchy Process (AHP). Skripsi. Institut Teknologi Sepuluh Nopember.

Mori, K., Sosrodarsono, S., dan Takeda, K. (2016): Hidrologi untuk Pengairan. Jakarta: Pradnya Paramita.

Peta Wilayah Kota Semarang diperoleh dari situs internet: http://www.semarangkota.go.id. Diunduh pada tanggal 23 Oktober 2018, Pukul 18.53 WIB. 
Situmorang, R. (2015): Penerapan Model EPA SWMM 5.1 untuk Evaluasi Saluran Drainase di Darmawangsa Residence Bekasi Jawa Barat. Skripsi. Institut Pertanian Bogor.

Suripin (2004): Sistem Drainase Perkotaan yang Berkelanjutan, Penerbit Andi, Yogyakarta. 